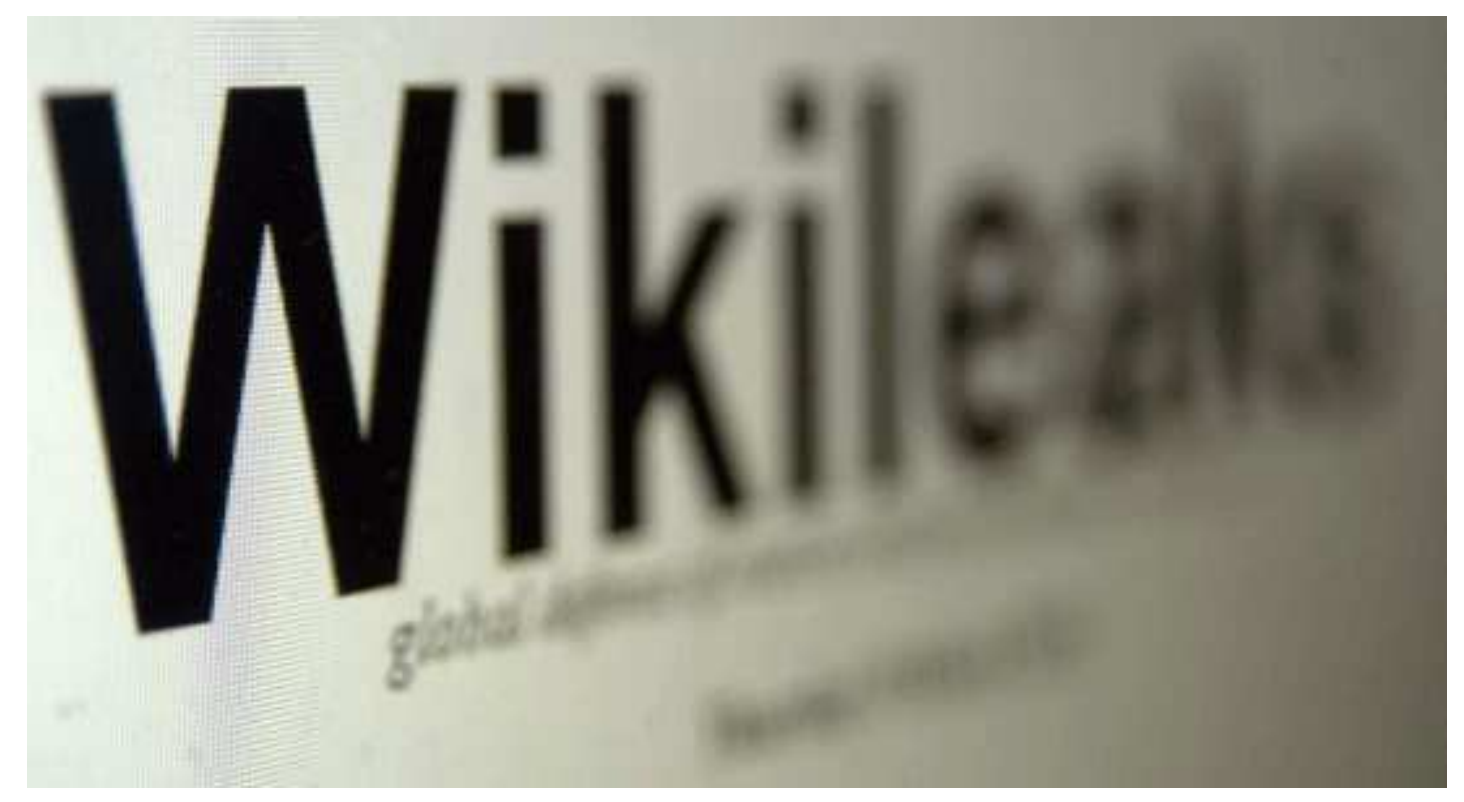

\title{
Wikileaks: Discurso e confidencialidade em arquivos ${ }^{1}$ \\ Wikileaks: Discourse and Confidentiality in Files
}

Andressa Carvalho Silva-Oyama*

\section{Resumo}

O Wikileaks é um site que disponibiliza em rede virtual arquivos confidenciais/sigilosos de autoridades governamentais ou arquivos "sensíveis" - para as relações políticas e diplomáticas. Tal publicidade é dada sem o aval daqueles que são os responsáveis pela confecção desses arquivos, ou que neles são mencionados, o que gera a discussão sobre os limites entre o direito de informação e a privacidade na vida pública. Este artigo investiga os discursos sobre esses arquivos, enquanto documentos sigilosos, bem como analisa as relações entre os sujeitos de mídia e da Wikileaks, buscando evidenciar as legitimidades de cada posicionamento, assim como sua relação com o Estado e com a sociedade.

Palavras-chave: discurso; wikileaks; arquivos (sigilosos); mídia

\section{Abstract}

Wikileaks is a website that offers virtual networked confidential/secret files of government officials or files that are "sensitive" - for political and diplomatic relations. Such publicity is given without the approval of those who are responsible for making these files or who are mentioned in them, which leads to a discussion about the boundaries between the right to information and privacy in public life. This article investigates the discourses about these files, as sensitive documents, and analyzes the relationship between the subjects of media and of Wikileaks, aiming to highlight the legitimacy of each positioning, as well as its relationship with state and society.

Keywords: discourse; wikileaks; (confidential) files; media

\footnotetext{
${ }^{1}$ Agradeço ao Prof. Dr. José Horta Nunes (UNESP/ SJRP) pela orientação para fins de Qualificação Especial, bem como pela dedicação e atenção com contribuições valiosas para a elaboração do presente artigo.

* A autora é doutoranda em Estudos Linguísticos, Universidade Estadual Paulista - São José do Rio Preto. e-mail: and_carsyl@yahoo.com.br Rua Paulo Vidalli, 92, Higienópolis- São José do Rio Preto - SP - CEP: 15085-470
} 


\section{Introdução}

Segundo Orlandi, "a ideologia interpela o indivíduo em sujeito e este submete-se à língua significando e significando-se pelo simbólico na história” (1999, p. 10). Assim, inserido em uma Formação Discursiva - definida pela autora como espaço onde o sentido é determinado e onde se dá a identificação do sujeito -, é impelido pela determinação, pela "injunção a dar sentido", que, por fim, refletem a sua interpelação em "um gesto, um movimento sócio-historicamente situado" (p. 13). Por esses motivos que, ainda que um discurso se julgue como neutro, cabalmente produzirá sentidos de acordo com uma perspectiva ideológica. Isso traz à mente o constante debate sobre os limites de direito à informação nos meios de imprensa, que ganhou nova perspectiva com o caso Wikileaks. Capa de edição da revista Veja de dezembro de 2010, Julian Assange, fundador do Wikileaks, tem sua imagem caracterizada à semelhança de um homem-bomba. No entanto, os "explosivos" que envolvem seu corpo são uma retratação do próprio ícone do Wikileaks - uma ampulheta com um globo terrestre em cada extremidade, sendo o de cima escuro e o de baixo claro - além de haver vários pen drives dispostos na parte de cima do "cinto bomba". Por fim, o tradicional detonador do dispositivo, na mão de Assange (o qual se encontra em uma postura que sugere ataque), é substituído por um mouse. A frase impressa na capa chama a atenção do sujeito leitor para o que foi denominado 'Guerras Digitais'.

O site, desde sua criação, tem disponibilizado documentos ou arquivos que permitem o acesso a informações sigilosas que, em tese, mantém o anonimato daqueles que as disponibilizaram. Tal fator, cabe ressaltar, acaba por trazer à tona diversos documentos que, por motivos variados, geram polêmicas e influem, inclusive, em questões diplomáticas. Tem-se, por exemplo, o caso de diversos telegramas de diplomacia que, por versarem em tom de informalidade e "intimidade", expuseram diversos comentários “sensíveis" para a 'imagem' de países e governantes. Tais fatos parecem ser decorrentes da atual cibercultura, a qual amplia não só a possibilidade de construção, mas também de disponibilização (e por que não de vazamento) de arquivos, formando conjuntos que, ao mesmo tempo em que são amplamente localizáveis, são também facilmente elimináveis e possuem alto grau de propagação. Foi em meio a esse cenário que o Wikileaks ganhou lugar como um espaço de publicação de informações confidenciais, gerando embate entre confidencialidade e direito de informação, o qual 
acaba por configurar um lugar no qual o sujeito assume uma liberdade, "o sonho democrático" (MAGALHÃES; MARIANI, 2010).

Diante da repercussão que teve o fato - uma vez que Julian Assange foi preso (ainda que sob acusação diversa, uma vez que o governo dos Estados Unidos estava em busca de argumento legal para processá-lo) e que os diversos sites que arrecadavam fundo para a organização cancelaram seus serviços relacionados à Wikileaks (ainda que sob protestos e invasões de hackers) - busca-se, no presente trabalho, discorrer acerca dos gestos de interpretação sobre esses arquivos (sigilosos) e a circulação de seu sentido em diferentes discursos sobre esse objeto. Para isso, primeiramente, será exposto um breve dispositivo teórico; em seguida, será descrito o processo de seleção do corpus, bem como o procedimento de análise, que virá em sequência. Por fim, serão apresentadas as considerações finais.

\section{Sujeito e arquivo.}

O discurso, de acordo com a perspectiva da Análise do Discurso (AD), é efeito de sentidos que se materializa na língua. Por esse motivo, é necessariamente marcado pela significação que adquire não em função daquilo que o sujeito quis dizer, mas sim pela relação entre o dizer e a condição sócio-histórica da materialização desse dizer, constituindo-se, assim, por diversos outros discursos.

Desse modo, o sujeito tem somente a ilusão de que é dono do seu dizer. Como afirma Orlandi, há um duplo momento na constituição da subjetividade. No primeiro, o indivíduo, interpelado pela ideologia, é sujeito, 'forma-sujeito histórica', o que produz o assujeitamento; no segundo (que não necessariamente é posterior, dado que não se trata de uma perspectiva cronológica), o sujeito se estabelece em função das relações sociais guiadas pelo Estado, o qual "individualiza forma-sujeito histórica, produzindo diferentes efeitos no processo de significação" (ORLANDI, 1999, p. 14), ou, como afirma Magalhães e Mariani, trata-se de uma relação "visível e a partir da qual é possível adaptar o sujeito ao social” (2010, p. 3). A passagem do primeiro para o segundo momento supõe a inscrição naquilo que é simbólico, "estabelecimento (e deslocamento) das formas de individua(liza)ção do sujeito em relação ao Estado" (MAGAlHÃES; MARIANI, 2010, p. 3). Todo o discurso, então, seria regido por forças ideológicas que atuariam determinando o que deve ou não ser dito. Como afirma 
Magalhães e Mariani (op.cit), "meus significantes [...] estão constituídos e afetados pelo Outro: para emergir como sujeito falamos afetados pelo Outro (nesse sentido, a alteridade está em mim). O processo de subjetivação está atravessado pela materialidade significante do outro" (p. 5).

É importante ressaltar que, para estudar os gestos de interpretação sobre os arquivos, é necessário, primeiramente, observar o sujeito inserido nas condições gerais de produção. Como afirma Pecheux, "todo enunciado é intrinsecamente suscetível de tornar-se outro, diferente de si mesmo, se deslocar discursivamente de seu sentido para derivar para outro" (1990, p. 53). Isso porque "as condições de produção incluem sujeito e situação" (ORLANDI, 2006). Estas condições, segundo a autora, podem ser pensadas tanto em sentido stricto (o aqui e agora do dizer) quanto em sentido lato (contexto ideológico e sócio-histórico). Esses dois contextos sempre funcionariam em conjunto. Neles, configura-se um sujeito que é projetado no discurso (ORLANDI, op.cit). Tal projeção, cabe ressaltar, dá-se em função das "formações imaginárias" presentes no discurso. Assim, estabelece-se um jogo de imagens, que inclui i) a que o sujeito faz de si mesmo; ii) a que o sujeito faz de seu interlocutor; iii) a que o sujeito faz de seu objeto de discurso. Igualmente, estariam presentes a imagem que o interlocutor do sujeito faz de si mesmo, daquele que lhe fala e daquilo que se fala, ou seja, do objeto do discurso (ORLANDI, op.cit).

É por esse motivo que o sentido de uma palavra não existe em si mesmo, mas é dado pelo contexto no qual é produzida. Por isso, a questão do arquivo, enquanto objeto do discurso, tem relevância no presente trabalho - dado que seu conceito recebe diferentes significações conforme o discurso em que é produzido. Pecheux afirma que a relação entre língua (como sistema passível de jogo) e a discursividade (efeitos linguísticos materiais na história) seria o "nó central de um trabalho de leitura de arquivo" (1997, p. 63). Falando sobre as culturas científicas e literárias e sobre suas pretensões sobre o arquivo, o autor afirma que o fato da língua permanecia subestimado, ou seja, "materialidade da língua desaparece" (p. 63). Por esse motivo, defende que se deve consagrar a materialidade da língua na discursividade do arquivo. Isso porque:

seria do maior interesse reconstruir a história desse sistema diferencial dos gestos de leitura subjacentes, na construção do arquivo, no acesso a documentos e a maneira de aprendê-los, nas práticas silenciosas da "leitura espontânea" reconstituíveis a partir de seus efeitos na escritura: consistiria em marcar e reconhecer as evidências práticas que organizam estas leituras, mergulhando a "leitura literal" (enquanto 
apreensão do documento) numa "leitura interpretativa - que já é uma escritura. Assim começaria a se constituir um espaço polêmico das maneiras de ler, uma descrição do "trabalho do arquivo enquanto relação do arquivo com ele mesmo, em uma série de conjunturas, trabalho da memória histórica em perpétuo confronto consigo mesma (p. 57)

Cabe ressaltar que, como afirmam Guilhaumou e Maldidier, o arquivo nunca é dado a priori. Isto quer dizer que uma leitura na qual se observam datas, nomes, etc. não seria suficiente. $\mathrm{O}$ arquivo, muito mais que simples referências "permite uma leitura que traz à tona dispositivos e configurações significantes" (1997, p. 164). O conceito pode ser aplicado também para a configuração sobre arquivo, enquanto material tecnológico, que, ao mesmo tempo em que - no caso dos documentos da Wikileaks configura-se como sigiloso, confidencial, estabelece-se também como fugaz, perdendose na dimensão sem fronteiras do universo em rede, abrindo-se a um leque de interpretações. Como afirma Nunes:

o arquivo não é visto como um conjunto de "dados" objetivos dos
quais estaria excluída a espessura histórica, mas como uma
materialidade discursiva que traz as marcas da constituição dos
sentidos. O material de arquivo está sujeito à interpretação e, mais do
que isso, à confrontação entre diferentes formas de interpretação e,
portanto, não corresponde a um espaço de "comprovação", onde se
suporia uma interpretação unívoca. $(2011$, p. 2$)$

Por isso que, ao se defrontar com arquivos que deveriam não-comunicar, abre-se para a interpretação do sujeito-outro que, em tese, estaria barrado na comunicação, no lugar de interlocutor para efeito discursivo.

Além disso, para entender como o arquivo influi na "ordem social", deve-se observá-lo, como menciona Nunes, como um espaço de polêmica, devendo as posições do sujeito serem consideradas na observação, mostrando-se a relação entre as interpretações, verificando-se os discursos aos quais se filiam. Para o autor, deve-se evidenciar "o movimento dos sentidos e dos sujeitos, no espaço tenso em que o real da interpretação pode tanto apaziguar quanto ameaçar"(idem). No presente caso, há a revelação de documentos sigilosos que são tidos como ameaçadores (dado que Assange foi descrito como "inimigo número um do Estado", pelo fato de trazer à tona documentos que ‘deveriam' permanecer não divulgados). Isso traz à mente a questão do silenciamento. Orlandi afirma que:

\footnotetext{
${ }^{2}$ Revista Veja, dezembro de 2010.
} 
O silêncio instala um trabalho que incide justamente sobre o jogo da identidade social, em outras palavras, sobre a dimensão pública do cidadão: ele é responsável diante da lei. Em consequência, a relação entre o que ele diz e o que ele não diz concerne à ética e ao político (1993, p. 110).

Orlandi continua sua teorização dizendo que, em termos de silenciamento ou censura, o sujeito não diz as coisas porque não sabe; ou seja, não é ausência de informação, mas interdição. Há um silêncio que se instaura na base da divisão dos sentidos, trazendo consequências para a política do dizer. Como afirma a autora, "o silêncio que é feito sobre uma certa região de sentidos é carregado de palavras a não serem ditas. E é por isto mesmo que elas significam" (p. 115).

Assim, haveria dois tipos de silêncio. Um deles denominado silêncio constitutivo, caracterizando-se por ser inerente à própria produção de sentido e por estar presente em toda a produção de linguagem; o outro silêncio seria expresso pela política do silêncio, a qual "produz um recorte entre o que se diz e o que não se diz" (p. 75). Esta política é que se busca analisar de modo a compreender os gestos de significação em torno dos sujeitos e sua posição discursiva sobre os arquivos no espaço Wikileaks.

\section{Metodologia}

Para levar a cabo a análise a que se propõe este trabalho, foram selecionados textos que versassem sobre sujeito, arquivo e silêncio. O corpus foi extraído de diversas fontes que discursavam ou traziam alguma informação sobre o tema Wikileaks. Uma delas foi o próprio site Wikileaks (o qual foi acessado em um site espelho). Trata-se de um site que funciona como servidor e gerenciador de arquivos. Fundado por Julian Assange, conta com a colaboração de diversas pessoas que possuem o intento de disponibilizar informações sigilosas para o público da rede em geral. Outro material foi coletado na edição de dezembro de 2010 da Revista Veja, a qual, publicada semanalmente, é editada por jornalistas no intento de informar. Destinada a leitores em geral, versa sobre acontecimentos e fatos do cotidiano, política, educação, entre outros temas. A edição analisada expôs o tema Wikileaks em capa, e teve 10 (dez) páginas dedicadas ao assunto. Além desses materiais, também foi analisada uma entrevista feita 
por Chris Anderson - no canal TEDtalks ${ }^{3}$ - a Julian Assange. Esse canal apresenta sua definição como sendo uma comunidade global que acolhe pessoas de todas as disciplinas e visa divulgar o que nomeiam como "ideias que valem compartilhar". Com esse objetivo, estabelece como seu interlocutor "o mundo" que, no caso, seria o mundo internauta. Por fim, também foi separada para análise a definição da Wikipédia ${ }^{4}$ sobre Wikileaks. Esse site, amplamente conhecido, é de edição livre e voluntária. Tem como objetivo ser uma enciclopédia virtual que difunde informações também para o universo em rede. Como não há "um” sujeito - único e exclusivo - para a edição, é marcada pelo estatuto de construção coletiva de conhecimento.

A análise apresentada neste trabalho partiu dos discursos de cada um desses meios midiáticos sobre o tema. Verificou-se quem são os sujeitos, para quem falam, o que falam, sobre o que falam e a partir de qual posição. Desse modo, também foram observados os efeitos de sentido que poderiam ser gerados em cada caso. Assim, por meio do corpus citado, busca-se verificar como se configuram os discursos sobre os sujeitos e sobre o objeto desse discurso, a saber, informações sigilosas.

\section{Condições de produção: o que é Wikileaks}

Diante da repercussão que teve o site com a sua divulgação de informações sigilosas, vários foram os meios midiáticos que versaram sobre o tema. $\mathrm{O}$ embate lançado entre informação e confidencialidade levou a discursos diversos, cada um segundo um posicionamento discursivo. O lugar Wikileaks é apresentado pela Wikipédia Brasil como um site que se dedica a publicar informações vazadas. Já nessa definição, encontra-se uma caracterização do discurso como algo que teria inconsistência material, dado que vaza. A posição, então, é a de que esse discurso seria realmente algo que não "coube", que "vazou" ou "escapou" de seu espaço de circulação, de sua simetria enquanto produtor de sentidos em uma determinada configuração social. Ressalta-se que antes da descrição, expõe-se uma nota:

Nota: WikiLeaks não está associado à Wikipédia nem à Wikimedia Foundation.

\footnotetext{
${ }^{3}$ Sigla de Technology, Entertainment, Design. Acesso em 19 de fevereiro de 2011.

${ }^{4}$ Acesso em 18 de fevereiro de 2011.
} 
É possível observar que o dizer já configura um lugar de não confluência. Ou seja, já se estabelece que um possível não-dito poderia deixar margens a interpretações errôneas. Tenta-se barrar o equívoco, significando 'o que não é' para mostrar 'o que não se diz', evitando-se, então, o estabelecimento de um paralelo ou uma associação. O sujeito editor, no caso, mostra o que é denominado por Orlandi(2001) de estabelecimento (e o deslocamento) das formas de individua(liza)ção do sujeito em relação ao Estado: apesar de ser "dono de seu dizer" - uma vez que assume o papel de editor da Wikipédia -, adapta-o às normas sociais e vigentes, dado que seu silenciamento levaria à interpretação de conexão entre o site enciclopédico e o site "de vazamentos". O discurso se inicia em uma formação que se pretende não como neutra, mas como isenta. Há um sujeito que fala, que assume o discurso enquanto editor, mas sua posição seria somente a de alguém que descreve e que, apesar de também publicar arquivos e informações na internet, não possui ligação com a prática Wikileaks.

Interessante notar que a própria formatação dessa nota, que se dá ao início da página - diferentemente das demais 59 , que são apresentadas ao final do texto -, em tamanho de letra maior e em negrito. São três diferenciações que evidenciam o discurso da fundação Wikipédia. Ou seja, o objetivo parece ser o de ressaltar que, apesar de ter o nome semelhante (wiki está tanto em Wikipédia quanto em Wikileaks), a fundação Wikipédia não possui qualquer relação com a Wikileaks. O discurso de Wikipédia se fundamenta em um posicionamento informativo, alguém que fala para um sujeito que busca saber, de maneira 'contemplativa', sobre Wikileaks. A definição dada na Wikipédia apresenta ainda que

Segundo o site da WikiLeaks, entre seus fundadores estão dissidentes chineses, jornalistas, matemáticos e tecnólogos de empresas start-up dos EUA, de Taiwan, da Europa, Austrália e África do Sul. Os organizadores afirmam que a WikiLeaks é uma entidade autorregulada.

A heterogeneidade marcada (AUTHIER-REVUZ, 1990) - "segundo o site" -, nesse trecho, busca evidenciar que o discurso de definição não é feito por quem editou a Wikipédia, mas sim pelos próprios fundadores. Essa passagem também expõe, então, um discurso que busca distanciar-se ou isentar-se. A informação é apresentada com a voz do outro marcada, totalmente diferente da nota na qual o discurso é assumido como seu: um papel que busca a segurança de um discurso duplamente legitimado: ao citar o discurso dos fundadores e ao se resguardar explicitamente. 
Interessante pontuar também que a presença de "wiki" no começo do nome de ambas as organizações (Wikipédia e Wikileaks) traz em si uma identificação, resultante de uma significação imaginária, explicitada pela presença de um mesmo significante. A ressalva feita pela Wikipédia é no sentido de mostrar que o simbólico é diferente do efeito de sentido que poderia ser estabelecido por leitores "desavisados". No entanto, esse "desaviso" marca somente a remissão à memória contextual desses sites: ambos falam a partir de um espaço digital. O mesmo significante gera o efeito de sentido que é dado pela memória digital dos leitores internautas. O simbólico "wiki”, então, é marcado pela Wikipédia de modo a estabelecer um contraste com esse imaginário, para negá-lo e, consequentemente, negar a identificação e a filiação.

Ressalta-se que a coleta de dados para investigação sobre o discurso do próprio site Wikileaks a respeito de sua configuração levou ao encontro de diversos sites espelhos. Isso porque, devido ao vazamento de telegramas diplomáticos anteriormente mencionados, o domínio www.wikileaks.org havia sido retirado do ar. No entanto, vários foram os sites que reproduziram, em domínios diferentes, o mesmo conteúdo do site original. Por isso são denominados espelhos: o conteúdo se mantém, mas o domínio é outro. Em um dos espelhos (http://wikileaks.ch/ ${ }^{5}$ ) encontrou-se a definição dos organizadores sobre a Wikileaks:

WikiLeaks é uma organização de mídia sem fins lucrativos dedicada a trazer notícias e informações importantes para o público. Nós fornecemos uma maneira inovadora, segura e anônima para vazamento de informações de fontes independentes ao redor do mundo a nossos jornalistas. Nós publicamos material de conteúdo ético, político e histórico, mantendo o anonimato da identidade das fontes, proporcionando assim uma forma universal para a revelação de injustiças reprimidas e censuradas. ${ }^{6}$

É possível observar que, ao início, Wikileaks é tratada como terceira pessoa do discurso: não há um 'eu' individual ou coletivo que se posicione a respeito do conceito. Tal postura se modifica na segunda oração, na qual um 'nós' assume o discurso, o que também pode ser observado no uso do possessivo 'nossos'. Assim estabelece-se um discurso de uma coletividade, o que legitimaria ainda mais a organização.

\footnotetext{
${ }^{5}$ Acesso em 19 de fevereiro de 2011.

${ }^{6}$ No original: "WikiLeaks is a non-profit media organization dedicated to bringing important news and information to the public. We provide an innovative, secure and anonymous way for independent sources around the world to leak information to our journalists. We publish material of ethical, political and historical significance while keeping the identity of our sources anonymous, thus providing a universal way for the revealing of suppressed and censored injustices."
} 
Outra caracterização sobre a Wikileaks pode ser observada na entrevista dada pelo fundador, Juliam Assange ${ }^{7}$, ao TED:

Entrevistador: Bem vindo, Julian Foi divulgado que o WikiLeaks, seu bebê, divulgou... nos últimos anos divulgou mais documentos sigilosos do que o resto de toda a mídia do mundo junta. Isso pode ser verdade?

Observa-se, primeiramente, que o entrevistador individualiza a organização, ao colocar o fundador como sendo o "pai” de um bebê denominado Wikileaks. O discurso marcado por uma afetividade de um discurso familiar ou maternal - traz uma individualização da organização na pessoa de Assange, que é, assim, caracterizado como o sujeito unívoco desse discurso "que leva à revelação de informações sigilosas". Além disso, estabelece-se uma relação dicotômica entre o discurso da mídia e o discurso da Wikileaks, individualizado em Assange. Ora, a mídia caracteriza-se por informar; a Wikileaks, por "divulgar documentos sigilosos". Esse paralelo coloca em mesmo nível o que possui características diferenciadas, o que será visto posteriormente neste trabalho.

\section{Gestos de interpretação sobre arquivos}

Como foi apresentado na fundamentação teórica, segundo Nunes (2011), há todo um processo de leitura e interpretação de arquivo no qual as posições históricas e sociais não devem ser descartadas. Além disso, o arquivo pode tanto apaziguar, quanto ameaçar. Ressalta-se, no entanto, que, no presente trabalho, não são observados os discursos sobre arquivo enquanto memória de Estado, mas antes enquanto discurso não circulável, ou mesmo não 'informável'. Um discurso de arquivo que deveria permanecer no 'oculto', de modo a manter o 'equilíbrio social'.

Esse parece ser justamente o alvo da ruptura de ritual ideológico a que se propõe a Wikileaks. Seriam sujeitos que, não legitimados a publicar ou a fazer circular essa informação, romperiam com as barreiras de silenciamento local, levando a um impasse em Direito entre o que é ilegal e o que é aético. Há o 'empoderamento’ de uma posição discursiva que seria barrada ao sujeito. Como afirma Guimarães, "estar identificado pela divisão da língua é estar destinado, por uma deontologia global da língua, a poder dizer certas coisas e não outras, a poder falar de certos lugares de locutor e não de outros, a ter certos interlocutores e não outros" (2002, p. 21). Por esse motivo, nota-se que há a

\footnotetext{
${ }^{7}$ http://blogladob.com.br/geral/entrevista-legendada-com-julian-assange-criador-do-wikileaks/
} 
tentativa, por parte do (inter)locutor, de apoderar-se de determinada posição. Ressaltase, no entanto, que toda a seleção de vazamentos da Wikileaks também passa por um gesto de leitura para a formação dos "arquivos confidenciais". Isso porque não se trata de publicar qualquer arquivo privado, sigiloso ou confidencial, mas um arquivo confidencial que coloque em xeque o aparato Estado e suas relações. Há, então, um gesto de interpretação também baseado no Estado, mas ao revés: os limites impostos são confrontados. Tome-se novamente a definição dos arquivos dada pela Wikileaks:

(...) para trazer notícias e informações importantes para o público. (...)Nós publicamos material de conteúdo ético, político e histórico, mantendo o anonimato da identidade das fontes, proporcionando assim uma forma universal para a revelação de injustiças reprimidas e censuradas. ${ }^{8}$.

Um ponto a ser destacado é o uso das palavras 'notícias', 'informação' e 'material', que remetem ao discurso da própria mídia, já legitimado enquanto meio de informação; no entanto, é estabelecido um paralelo, ao final, entre essas palavras e 'injustiças reprimidas e censuradas'. Nesse ponto, a legitimidade informativa é transportada a um cenário de revelação de injustiças. Enunciado esse que estabelece um discurso que, além de informar, leva a um cenário de informação oculta e, como afirma Orlandi "há em todo sujeito social a vontade/ necessidade de saber" (2001, p. 143). Assim, estabelece-se um jogo que se configura nessa relação de produção de efeito de informação capaz de levar aquilo que é 'injusto', desconhecido, para o domínio de um sujeito estabelecido como não legitimado para obter tal informação.

Por isso que o uso do termo 'censuradas', especificamente, também salienta um discurso de "justiça": a Wikileaks se denomina como aquela que vai dar ao sujeito leitor, enquanto ser social, a informação que lhe deveria ser acessível, mas que lhe foi barrada. Claro é que se houvesse sido empregado outro termo como, por exemplo, 'confidencial' ou mesmo 'sigiloso', haveria também a marca de "segredo". No entanto, 'censura' constrói um sentido de negação de direitos, de barramento do saber que é devido. Coloca-se, assim, que o sujeito seria legitimado para obter tais informações se não houvesse os limites do Estado.

\footnotetext{
${ }^{8}$ No original “(...) to bringing important news and information to the public. (...) We publish material of ethical, political and historical significance while keeping the identity of our sources anonymous, thus providing a universal way for the revealing of suppressed and censored injustices"
} 
Ademais, Orlandi afirma que:

No arquivo, o dizer é documento, atestação de sentidos, efeitos de relações de forças (...) o arquivo repousa sobre o realizado, menos sobre o que pode e muito mais sobre o que deve ser dito. No arquivo há assim um efeito de fechamento. Se o interdiscurso se estrutura pelo esquecimento, o arquivo é o que não se esquece (ou o que não se deve esquecer). Se no interdiscurso fala uma voz sem nome, no arquivo fala a voz comum, a de todos (embora dividida). (2003, p.14)

Como o arquivo repousa sobre o realizado, tem-se que os arquivos, enquanto documentos sigilosos, vão além do que deve ser dito. Nesse caso, há documentos, forças e relações de poder que não deveriam, em tese, ser voz comum, e menos ainda interpretação para todos. Tem-se, certamente, um fechamento. No entanto, trata-se de um fechamento dual: de realizado (enquanto acabado) e de circunscrição de interlocutores: essa última se configura, no caso Wikileaks, em uma 'abertura' que busca evidenciar o primeiro fechamento, de modo a elucidar aquilo que não se deve esquecer para além das fronteiras de sujeitos legitimados.

O silenciamento local, de interdição do dizer (ORLANDI, 1993), estaria sendo colocado em evidência, quebrando o ritual ideológico e estabelecendo posições discursivas e interpretativas outras para tais informações - posições estas antes barradas. A Wikipédia, por sua vez, apresenta as seguintes definições para arquivo:

WikiLeaks é uma organização transnacional sem fins lucrativos, sediada na Suécia, que publica, em seu site, posts de fontes anônimas, documentos, fotos e informações confidenciais, vazadas de governos ou empresas, sobre assuntos sensíveis.

A qualificação técnica dos arquivos (documentos, fotos) recebe a adjetivação de 'informações confidenciais'. O discurso que se confidencia é aquele feito por um sujeito, que, a partir de sua posição, busca circunscrever seu dizer a uma esfera social limitada. Observe-se que as informações são caracterizadas como 'vazadas'. Ou seja, o jogo de sentidos, antes circunscrito a determinado grupo, é levado a público. Um discurso que, produzido no segredo, é divulgado, levando a interpretações diversas. Outro ponto a ser destacado é o uso do adjetivo abstrato 'sensíveis' para o substantivo 'assuntos'. A relação que se estabelece é a de que o jogo de interpretação seria passível de ser ferido, ser infringido. O que seria uma informação/assunto sensível? Esse discurso da Wikipédia, vale ressaltar, é encontrado em várias outras fontes midiáticas. Essa relação de sensibilidade leva a notar, novamente, o limite entre o discurso do ilegal 
e do aético: qual o sujeito que disponibiliza essa informação? Ele tem legitimidade para tal? Por que a faz circular? O que circula?

As respostas a essas perguntas fazem perceber um lugar de significação no qual o sentido de clareza, de informação real, sem 'máscaras' busca estatuto de veracidade. Veracidade essa que não é somente informativa, mas também que leva a quebra do que seria, em termos de Orlandi, a retórica da dominação. Explicita-se um discurso que se pretende como 'libertador', como aquele que rompe o "recorte do dizer", que se nomeia como rompendo "o silenciamento como forma de não calar, mas de fazer dizer 'uma' coisa, para não deixar dizer 'outras"” (1993, p. 55). Pretensão que não ultrapassa os limites da própria ideologia, uma vez que se define em função do que é legal, do que é permitido ou não, do que deve ser ou não silenciado.

Essa pretensão também coloca em evidência as Formações Discursivas (FD) da mídia e da Wikileaks. A mídia possui uma relação com o Estado, de modo que, ainda que possa ser considerada como "crítica" ou mesmo "parcial" em alguns temas, não tem o objetivo de explicitar discursos sigilosos, "segredos de Estado". Ora, no Brasil, há legislação sobre o sigilo e classificação de arquivos (Lei 8.159/1991 e Decreto 4.553/2002). Não é o intuito discutir sobre o caráter desses arquivos, mas sim salientar que há um ritual pré-estabelecido em relação a manter em confidencialidade tais documentos. Nesse ritual se insere a FD da mídia, uma vez que não se busca violar o que é protegido, sigiloso. Suas condições de produção discursiva, então, são o próprio Estado: a mídia fala nos limites "pré-estabelecidos" para um público também já legitimado pelo aparato Estado. Ou seja, há não-ditos que expõem o silenciamento que cerceia o limite desse discurso.

A FD da Wikileaks, no entanto, tem como objetivo justamente extravasar esse não-dito da FD da mídia e, por isso, versa em termos de confidencialidade vazada. Não é uma informação que vai em consonância com os interesses do Estado, mas também não se trata de explicitar o silenciamento deste. Antes, o que se tem é o discurso que busca evidenciar não-ditos de modo a questionar ou a mesmo burlar os poderes e as relações consolidadas. Assim, estabelece-se uma relação que se pretende como "atemporal", como "universal", sem fronteiras. Não há o escopo no "que pode ou deve ser dito", mas sim há o estabelecimento de uma esfera discursiva pautada em "dizer o que não pode ou não deve ser dito". Ou seja, todo o discurso se pretende como independente do Estado e de seu cerceamento, no entanto, a própria definição do que 
pode ou não ser dito é constituída pelo Estado. A pretensão, então, estabelece-se num parâmetro no qual o Estado continua sendo o elemento de referência.

Isso porque a seleção do arquivo, como foi dito anteriormente, é feita com base nas informações que são passíveis de "abalar" estruturas, o status quo, como menciona a Veja (p. 160). Não se publicam arquivos confidenciais domésticos de um sujeito da sociedade sem relação de poder com o Estado, por exemplo. Assim, vê-se, nesse nãodito, que há uma ilusão de independência, de não cessão aos “ditames" ou regras que, na verdade, acaba passando pelo crivo do que é o Estado e de seu poder.

\section{Ativismo informativo}

Como mencionado ao início deste trabalho, a Revista Veja apresentou uma imagem caricaturada de Assange como um homem-bomba. Isso porque, como era de se esperar, o vazamento de documentos confidenciais abre margem para uma gama de interpretações e, diversas vezes, coloca em evidência o que deveria estar oculto aos "administrados" pelo Estado. Insurgem, então, problemas com relação a evidenciar o que deveria ser silenciado, o que gera preocupações para os produtores desses documentos. Tais preocupações, muitas vezes, tornam-se mesmo comparadas a 'terror', levando a um discurso que toca no democrático versus terrorismo.

Como mencionado, a ilusão de liberdade, o sonho democrático ao qual aspira o indivíduo é sempre definido em consonância com os limites do aparato ideológico, das normas e leis que regem o Estado e a sociedade. A citação de capa da revista define Assange como "o homem dos 250.000 segredos de estado", e, na descrição da imagem, há a frase:

Homem- bomba" - Numa prévia das guerras digitais do século XXI, os hacktivistas reagem à prisão de Assange, lançando uma onda planetária de ataques.

Observa-se o uso do termo "hacktivistas", uma cunhagem de hackers com ativistas. O discurso do ativismo faz pensar em agir por uma causa, como fome, paz mundial, sustentabilidade ou mesmo uma causa política. No entanto, nota-se que há o uso de palavras do campo bélico - "ataque", "guerras", "homem-bomba". Isso porque o fato de serem hackers traz à memória todo o discurso de invasores digitais, daqueles que burlam sistemas protegidos ou mesmo pegam informações confidenciais, o que, cabalmente, faz estabelecer uma associação entre Wikileaks e hacktivistas. O discurso 
da revista, cabe ressaltar, visa a um público que, em tese, busca informação. No entanto, a própria seleção dos fatos e do que vai ser dito sobre eles é relativizada, é orientada por uma posição. Nesse caso, pode-se notar que o discurso de "ativismo" é relativizado a uma semântica bélica, uma vez que, na página 160, ao informar sobre "as vítimas dos hacktivistas", a seção se inicia com "o vandalismo começou...”. Elucida-se, então, que, novamente, há um discurso de terror ou de guerra, dado que há vítimas (as operadoras de pagamento via Internet que recebiam doações para a Wikileaks). O uso do termo "vandalismo" também remete a uma formação discursiva que classifica a ação como ameaçadora. Cabe ressaltar que a reportagem menciona que não haveria ligações entre hackers e ativistas da seguinte maneira:

Espertíssimo, Julian Assange, de dentro da prisão londrina, mandou sua advogada [...] dizer que seu site não tinha nenhuma relação com Anonymous (nome atribuído ao grupo de hacktivistas). "O wikileaks não é uma organização de hackers. É uma editora e uma empresa jornalística", disse a advogada.

O uso do adjetivo "espertíssimo" já expõe uma marca de ironia que se materializa na escrita. Essa parte da notícia não vem em manchetes ou títulos, mas em um dos muitos parágrafos da matéria. Assim, nota-se que parece haver desconexão entre o que foi inscrito como manchete e o informado na matéria. Como afirma Guimarães, "ao reescriturar, ao fazer interpretar algo como diferente de si, este procedimento atribui (predica) algo ao reescriturado" (2002). Tal diferença também pode ser observada no uso do verbo "mandou": coloca-se Assange como sujeito que detém o poder, que é responsável, inclusive, pelo discurso de sua advogada.

Isso porque uma relação entre mídia versus Wikileaks pode ser observada no discurso da revista. A advogada de Assange afirmou que o site seria "uma editora e uma empresa jornalística”. Nota-se que a heterogeneidade marcada (AUTHIER-REVUZ, 1990) dada pela revista Veja se inicia com o adjetivo "espertíssimo", qualificando a ação de Assange. O discurso da advogada, no entanto, apesar de ser, em tese, um discurso legitimado, dado que é um sujeito que fala "de acordo com a lei", "em termos legais", acaba por ser infirmado, isto é, quebra-se o que ele teria de legítimo devido ao fato de estar inscrito em uma ordem de um sujeito classificado como espertíssimo.

Interessante notar, ainda no excerto supracitado, que a Wikileaks, por sua vez, se reconhece como uma empresa jornalística, como uma editora. No entanto, é importante ressaltar que uma empresa jornalística sempre tem o seu discurso pautado no que seria 
'divulgável': são sujeitos que não interpretariam a notícia, mas somente a reproduzem. O objeto é sempre algo do real, fatos que se inscrevem na história e que seriam somente descritos. Assim, os leitores - como interlocutores de meio informativo legitimado, firmado e em tese não silenciado politicamente -, receberiam todas as informações que necessitariam sobre o mundo. Mas a Wikileaks coloca em xeque justamente essa questão de necessidade de informação. O seu discurso não seria legítimo, dado que toca em informações íntimas, confidenciais, que deveriam ser circunscritas a um universo restrito justamente pelo seu caráter sigiloso. Disponibilizam-se arquivos que seriam expostos a sujeitos desautorizados, que não teriam status ou posicionamento social para interpretá-los. Novamente, o arquivo que ameaça. Como afirma Orlandi, "proíbem-se certas palavras para se proibirem certos sentidos [...] Como, no discurso, o sujeito e o sentido se constituem ao mesmo tempo, ao se proceder desse modo se proíbe ao sujeito ocupar certos 'lugares', ou melhor, proíbem-se certas 'posições’ do sujeito” (1993, p. 78).

A partir dessa posição, os sujeitos que contribuem para o site não possuem o estatuto de jornalistas; no entanto, levam informações (legitimidade até então dada somente à imprensa). Assange, em resposta à pergunta sobre se teria divulgado mais documentos que a mídia, contesta:

É, isso pode ser verdade? É uma preocupação -- não é? -- Que o resto da mídia do mundo esteja fazendo um trabalho tão ruim que um grupinho de ativistas consegue publicar mais informações desse tipo do que o resto da imprensa mundial junta.

Assange assume um discurso crítico à mídia, colocando em pauta uma dicotomia que pode ser tida entre ativistas Wikileaks versus imprensa. Observa-se que, assim, ele caracteriza a imprensa como sendo não informativa e atribui ao seu trabalho uma qualificação negativa ao mesmo tempo em que afirma assumir esse trabalho por falta de competência daqueles que deveriam fazê-lo. Assange parece ter a ilusão de levar aos sujeitos liberdade de expressão (MAGALHÃES; MARIANI, op.cit). Assume-se como representante desse grupo que fala não a um público desautorizado de interpretar as informações sigilosas, mas antes ao público da imprensa, legitimados para receber informações, fatos, de descrição do real. Essa relação, entretanto, não é observada na definição dada pelo próprio site da Wikileaks na seção 'sobre': 
Nós fornecemos uma maneira inovadora, segura e anônima para vazamento de informações de fontes independentes ao redor do mundo a nossos jornalistas $^{9}$

Nesse enunciado, há uma relação entre Wikileaks e jornalismo que não estabelece uma dicotomia: eles dariam informações seguras para que os jornalistas a informassem. Assim, nota-se que, no discurso da própria Wikileaks, eles se assumem como objeto, como o fato a ser relatado, que, por isso, poderia ser revelado e discursado pelos jornalistas.

Em outro trecho da entrevista dada ao TED, ao comentar sobre um relatório de inteligência vazado no Quênia ao público de maneira informal e que teria mudado o rumo das eleições, o entrevistador indaga "Puxa, então o seu vazamento mudou substancialmente o mundo?" e Assange responde "Sim". Observa-se que o vazamento dado pelo site é atribuído ao fundador. Não há o discurso da coletividade apresentado na descrição do site, que identifica todos os vazamentos como sendo "nós". A relação de interpretação que se estabelece parece tentar colocar em jogo o que seria silenciado: realmente Assange assume todos os vazamentos? Com sua resposta, o não-dito expõese pelo fato de que não foi mencionada a coletividade, os organizadores, nem a própria Wikileaks. Assange se assume como um sujeito que, nesse caso, por quebrar o ritual ideológico de censura do Estado, teria mudado o andamento dos acontecimentos.

Observa-se, então, que Assange empossa o dizer, a autonomia, mostrando-se como um sujeito detentor do poder de expor o que deveria estar oculto. Essa singularização também é dada pela revista Veja:

Assange talvez não seja nem o herói nem o vilão da alegoria medieval do bem e do mal. Mas certamente é, nesse momento, o primeiro inimigo público do Estado na era digital - ou dos estados, dos poderes constituídos, do status quo.

O discurso novo, sigiloso, sensível, desestabiliza os discursos legitimados. Classifica-se, então, Assange como o inimigo do Estado, do status quo. Classificação essa que remete justamente ao aparato ideológico que dita os silêncios, as relações de poder, o que deve ser dito ou não dito. Como afirma Orlandi:

Por seu lado, as relações de poder estão simbolizadas em relações de força presentes no jogo de sentidos. Entra então em cena o desejo de clareza

\footnotetext{
${ }^{9}$ No original "We provide an innovative, secure and anonymous way for independent sources around the world to leak information to our journalists."
} 
(certeza): faz parte, da encenação retórica do poder, advogar a clareza, a transparência, praticando assim o apagamento, o silenciamento dos outros sentidos possíveis. (2001, p. 154)

Seria essa transparência que acaba por apagar outros sentidos o que objetiva quebrar a Wikileaks. No entanto, toda ruptura só existe porque é estabelecida relativamente ao que é poder. Não há liberdade de sentidos e de interpretação, mas somente o embate entre forças de silenciar e de evidenciar sujeitos e significados. Não obstante, nota-se que, de fato, o vazamento coloca em xeque relações estabelecidas e consolidadas, transparências que acabam mostrando sua opacidade face à publicação daquilo que, em tese, deveria ser secreto. Ademais, elucida-se e fomenta-se a discussão entre os que possuem ou não o direito à interpretação, ao arquivo.

\section{Considerações finais}

Neste artigo, buscou-se evidenciar a noção de arquivo, enquanto documento sigiloso, e os efeitos de sentido nos gestos de interpretação sobre ele. As teorias sobre leitura e interpretação de arquivo nesse contexto e a análise, segundo a Análise do Discurso, possibilitaram perceber que, novamente, o Estado é o elemento de referência. Tem-se, no discurso da Wikileaks, que a mídia é cerceada ou limitada pelo Estado, sendo legitimada somente para investigar e disponibilizar informações que não forem confidenciais ou vazadas. O discurso da Wikileaks trata tal silenciamento em termos de censura, de confidencialidade e de vazamento, e busca, assim, o confronto com o Estado, falando desde uma posição que se pretende como independente, mas que, na verdade, traz em seu discurso gestos de interpretação e de seleção de arquivos com base no que é definido pelo Estado como passível de ser ou não dito.

Isso porque os não-ditos da Wikileaks também permitem visualizar essa filiação ao revés: não se diz o que não é passível de chocar, de "abalar as estruturas" dos rituais sociais já estabelecidos. Tal objetivo não é encontrado no discurso da Wikipédia que, para se "resguardar", nega a filiação imaginária - identificação por meio de wiki - ao Wikileaks em nota inicial e destacada. O discurso da revista Veja, por sua vez, na reinterpretação do dizer, acaba por expressar gestos de leitura e de interpretação sobre o caso, classificando as ações dos hacktivistas com adjetivos que denotam um posicionamento. 
Cabe destacar, por fim, que os documentos sigilosos, enquanto arquivos disponibilizados na rede, perdem seu estatuto de confidencialidade. Ao serem disponibilizados, abre-se o leque de circulação e, consequentemente, de interpretações dantes não-legitimadas para a interlocução dessa informação. Assim, os sujeitos prendem-se no imaginário de que possuem acesso ao ideal democrático. Liberdade de informação, de expressão e de conhecimentos. Nesse cenário, o discurso sobre arquivo ganha outra significação. Informação que ameaça quebrar rituais e discursos consolidados, colocando em xeque relações e sujeitos na era da informação. Como o caso Wikileaks ainda é recente, resta muito a ocorrer, e, porque não, a ser analisado discursivamente.

\section{Referências Bibliográficas}

AUTHIER-REVUZ, J. 1999. Heterogeneidade(s) enunciativa(s). Cadernos de estudos lingüísticos, Campinas, UNICAMP - IEL, n. 19, p. 25-42, jul/ dez.

GUILHAUMOU, J.; MALDIDIER, D. 1997. Efeitos do arquivo. A análise do discurso do lado da história. In: Orlandi, Eni P. (org). [et al]. Gestos de leitura, Campinas, Editora da Unicamp (p. 163-88).

GUIMARÃES, E. 2002. Enunciação e acontecimento. In: __ Semântica do acontecimento: um estudo enunciativo da designação. Campinas, Pontes (p. 7-32).

MAGALHÃES, B.; MARIANI, B. 2010. Processos de subjetivação e identificação: ideologia e inconsciente. Linguagem em (Dis)curso, Palhoça, SC, v 10, n. 2, p. 391-408, maio/ago.

NUNES, José Horta. Leitura de arquivo: historicidade e compreensão. Disponível em: http://www.discurso.ufrgs.br/sead2/doc/interpretacao/Jose_horta.pdf. Acesso em: 29 de março de 2011.

ORLANDI, E. P. 1993. As formas do silêncio: no movimento dos sentidos. 2. Ed. Campinas, Editora da Unicamp. 16, maio. 1999. Do sujeito na história e no simbólico. Escritos, Campinas, SP, nº 4, p. 112001. Boatos e silêncios: os trajetos dos sentidos, os percursos do dizer. IN: Discurso e texto: formulação e circulação dos sentidos. 2. ed. Campinas, Pontes (p. 127-40). 
2001. Palavras ao Vento ou o poder e o vento. IN:

Discurso e texto: formulação e circulação dos sentidos. 2. ed. Campinas, Pontes (p. 141-8).

2003. Ler a cidade: o arquivo e a memória. In: ORLANDI, E. (Ed.). Para uma enciclopédia discursiva da cidade. Campinas, Pontes (p. 7-20).

2006. Análise do discurso. In: ORLANDI, E.; LAGAZZI-RODRIGUES, S. (orgs.) Introdução às Ciências da Linguagem: discurso e textualidade. Campinas, Pontes.

PÊCHEUX, M. 1990. O discurso: estrutura ou acontecimento? Campinas, Pontes.

1997. Ler o arquivo hoje. In: Orlandi, Eni P. (org). [et al]. Gestos de leitura, Campinas, Editora da Unicamp (p. 55-65). 
Para citar essa obra:

SILVA-OYAMA, Andressa Carvalho; Wikileaks: Discurso e confidencialidade em arquivos. RUA [online]. 2013, no. 19. Volume 1 - ISSN 1413-2109

Consultada no Portal Labeurb - Revista do Laboratório de Estudos Urbanos do Núcleo de Desenvolvimento da Criatividade

http://www.labeurb.unicamp.br/rua/

Capa: WIKILEAKS. 2009. Disponivel em:

http://www.abc.net.au/reslib/200903/r350863_5041432.jpg

\section{Laboratório de Estudos Urbanos - LABEURB}

Núcleo de Desenvolvimento da Criatividade - NUDECRI

Universidade Estadual de Campinas - UNICAMP

http://www.labeurb.unicamp.br/

\section{Endereço:}

LABEURB - LABORATÓRIO DE ESTUDOS URBANOS

UNICAMP/COCEN / NUDECRI

CAIXA POSTAL 6166

Campinas/SP - Brasil

CEP 13083-892

Fone/ Fax: (19) 3521-7900

Contato: http://www.labeurb.unicamp.br/contato 